\title{
Comparison of oxidation status and antioxidant capacity of meat from surgically castrated and immunocastrated pigs, entire males and sows
}

\author{
František Ježek, Fouad Ali Abdullah Abdullah, Iva Steinhauserová, Radka Hulánková, \\ Gabriela Bořilová
}

University of Veterinary and Pharmaceutical Sciences Brno, Faculty of Veterinary Hygiene and Ecology, Department of Meat Hygiene and Technology

Received October 26, 2018

Accepted February 12, 2019

\begin{abstract}
The aim of the present study was to evaluate the influence of castration (surgical and immunological) and sex on lipid hydrolysis, oxidation and antioxidant capacity in selected muscles/cuts of pigs. Nine muscles/cuts from four groups of pigs (surgically castrated, entire males, immunocastrated and sow) were analysed. Free fatty acids (FFA) were analysed using standard methods according to CSN EN ISO 660. Thiobarbituric reactive substances (TBARS) were determined as malondialdehyde (MDA) equivalents and antioxidant capacity was evaluated by 2,2-diphenyl-1-picrylhydrazyl (DPPH) method . The highest content of FFA was observed in sows, detected to be significantly $(P<0.001)$ higher than in entire males. The highest content of TBARS was found in entire males; the content was significantly $(P<0.05)$ higher than in sows. Generally, the highest values of DPPH inhibition were detected in samples of surgically castrated pigs whereas the lowest values were observed in samples of entire males. Antioxidant capacity in musculus longissimus dorsi and backfat of surgically castrated pigs was significantly $(P<0.05)$ higher than in other evaluated groups of pigs. The study confirmed the differences in FFA and TBARS formation between analysed groups of pigs, probably due to differences in the fatty acid composition. The results of our study indicate that methods of castration have an effect on the antioxidant capacity of pork. These findings are of value to the meat industry.
\end{abstract}

Castration, pork, TBARS, DPPH, free fatty acids

Castration of male piglets represents the most common and usual method for boar taint prevention worldwide. Boar taint is an unpleasant odour caused mainly by the accumulation of androstenone, skatole, and to a lesser extent indole in the adipose tissue of male pigs (Fredriksen et al. 2009). In order to improve animal welfare practices, many consumers call for the prohibition of castration without anaesthesia. This was the reason for the European Union to introduce the Council Directive 2008/120/EC of December 2008 to protect pigs from traditional castration, imposing the condition of prolonged analgesia and/or anaesthesia during the surgical castration of pigs.

In various European countries young entire males are produced for slaughter. Usually smaller pigs are slaughtered, of about $80 \mathrm{~kg}$ of carcass weight. This prevents them from reaching sexual maturity and prevents tainted meats. The slaughtering of smaller pigs leads to production of lighter, leaner meat with more unsaturated fatty acids which can cause a problem during the meat processing (Bañón et al. 2004). Castration encourages fattening and can affect certain qualities of fresh meat (water retention capacity and colour) and cooked meat (cooking loss, aroma, taste, juiciness and tenderness) which are related to intramuscular fat (Babol and Squires 1995).

Owing to their high concentration of iron and sufficient levels of polyunsaturated fatty acids (PUFA) and cholesterol, pork meat and meat products are prone to lipid oxidation (Karwowska and Dolatowski 2014). One of the most important factor of meat shelf life is lipid peroxidation. The carbon-carbon double bonds of PUFA allow the formation of 
lipid free radicals by reactive oxygen species. This generates a chain reaction of more lipid hydroperoxides and more lipid free radicals. Breakdown of lipid hydroperoxides produces malondialdehyde (Grotto et al. 2009). In fact, thiobarbituric reactive substances (TBARS) are the standard method for detecting meat lipid oxidation by quantifying the amount of malondialdehyde present (Ripoll et al. 2018).

Hydrolytic changes in lipids cause the release of free fatty acids (FFA). Lipid hydrolysis could speed up lipid oxidation. Lipid oxidation in muscles may be associated with the cooperative actions of denatured proteins, release of metal ions, changes in enzymatic activities, or damages to cell membranes. The primary products of lipid oxidation are some hydroperoxides, which are of transitory nature and subsequently decompose to some small secondary oxidation-product molecules including TBA-reactive substances (Huang et al. 2015).

The oxidative stability of meat is dependent on the balance between antioxidants and pro-oxidants (such as PUFA concentration or free iron) (Florek et al. 2012). The animal's diet plays a major role in modifying the concentration of antioxidants, pro-oxidants and fatty acids in the meat (Serpen et al. 2012). A higher antioxidant content improves oxidation stability of meat. Low antioxidant levels in pig tissues containing high PUFA concentrations are due to the utilization of the antioxidant to control the oxidation status (Kouba et al. 2003). Previous results confirmed higher mean PUFA content in boars compared to castrates while no difference was observed between entire males and female pigs (Pauly et al. 2012). Immunologically castrated pigs have less back fat than surgical castrates (Dunshea et al. 2001; Boler et al. 2012), and as a result, it is more likely that their carcass fat will contain high concentrations of unsaturated fatty acids (Harris et al. 2018).

The aim of this study was to evaluate the influence of surgical castration and immunocastration on lipid hydrolysis, oxidation and antioxidant capacity of selected pig muscles/cuts in comparison to carcasses from entire males and sows.

\footnotetext{
Materials and Methods

Sampling

In total, 50 hybrids of Large White $\times$ Landrace (sow) $\times$ Duroc (boar) were used in this study. The experiment no. 23/2016 was approved by the Ethics Committee of the Central Commission for Animal Welfare of the Ministry of Agriculture of the Czech Republic. The pigs were classified into four groups that included: males castrated surgically (10 animals, age at slaughter $156 \mathrm{~d} \pm 16 \mathrm{~d}$ and live weight of $101 \mathrm{~kg} \pm 12 \mathrm{~kg}$ ), immunologically castrated males (Improvac ${ }^{\circledR}$ vaccine (Zoetis Inc., Parsippany, New Jersey) 10 animals, age at slaughter $160 \mathrm{~d} \pm 17 \mathrm{~d}$ and live weight of $107 \mathrm{~kg} \pm 13 \mathrm{~kg}$ ), entire males (20 animals, age at slaughter $164 \mathrm{~d} \pm 16 \mathrm{~d}$ and live weight of $111 \mathrm{~kg} \pm 10 \mathrm{~kg}$ ) and sows (10 animals, age at slaughter $159 \mathrm{~d} \pm 16 \mathrm{~d}$ and live weight of $102 \mathrm{~kg} \pm 9 \mathrm{~kg}$ ). Differences between the groups in age and live weight at the time of slaughter were not significant. The animals were slaughtered at an approved and registered slaughterhouse.

Double samples $(2 \times 5 \mathrm{~g})$ for antioxidant capacity determination were taken from the same location of the following muscles/cuts: 1) $\mathrm{m}$. serratus, 2) $\mathrm{m}$. longissimus dorsi, 3) $\mathrm{m}$. internal oblique, 4) $\mathrm{m}$. adductor, 5) jowl, 6) back fat, 7) $\mathrm{m}$. triceps brachii, 8) $\mathrm{m}$. biceps femoris, and 9) $\mathrm{m}$. semitendinosus. The samples were individually packaged in vacuum directly after cutting the carcasses $\left(24 \mathrm{~h}\right.$ after slaughtering) and kept frozen at $-70{ }^{\circ} \mathrm{C}$ till the day of analysis. Double samples (fresh tissue; $2 \times 100 \mathrm{~g}$ ) for FFA and TBARS determination were taken from same location of the following muscles/cuts: 1) neck, 2) $\mathrm{m}$. longissimus dorsi, 3) belly, 4) m. adductor, 8) $\mathrm{m}$. biceps femoris, and 9) $\mathrm{m}$. semitendinosus. Samples of 5) jowl, 6) back fat and 7) m. triceps brachii were not used for chemical analysis for their specific composition or similarity with other samples.
}

\section{Determination of free fatty acids}

Free fatty acids were determined in accordance with CSN EN ISO 660 (2015) by the titration method and expressed as the percentage of total fat as oleic acid.

Detemination of thiobarbituric acid reactive substances (TBARS)

The extent of lipid oxidation was evaluated on raw meat as TBARS. Ten grams of minced muscles were homogenised for $2 \mathrm{~min}$ with $95.7 \mathrm{ml}$ of distilled water and $2.5 \mathrm{ml}$ of $4 \mathrm{~N} \mathrm{HCl}$. The mixture was distilled until $50 \mathrm{ml}$ was obtained. Then, $5 \mathrm{ml}$ of the distillate and $5 \mathrm{ml}$ of TBA reagent $(15 \%$ trichloroacetic acid, $0.375 \%$ 
thiobarbituric acid) were heated in a boiling water bath for $35 \mathrm{~min}$. After cooling under running tap water for $10 \mathrm{~min}$, the absorbance was measured at $532 \mathrm{~nm}$ against an appropriate blank. The TBARS values were obtained by multiplying optical density by 7.8. Oxidation products were quantified as malondialdehyde equivalents (MDA mg $\mathrm{kg}^{-1}$ muscle) (Castellini et al. 2002).

\section{Determination of antioxidant capacity}

Free radical scavenging ability 2,2-diphenyl-1-picrylhydrazyl (DPPH) method was used to determine the antioxidant capacity according to Heilerova et al. (2003). Preparation of pork extract was performed according to Jung et al. (2010). Fifteen $\mathrm{ml}$ of 5\% trichloroacetic acid were added to $3 \mathrm{~g}$ of tissue sample and after homogenisation $10 \mathrm{ml}$ of chloroform were added. Fresh solution of radical stock solution was prepared each day. Solution of DPPH in methanol $\left(0.025 \mathrm{~g} \cdot \mathrm{l}^{-1}\right)$ was transferred into a $1 \mathrm{~cm}$ cuvette and the absorbance value $\mathrm{A}_{0}$ was measured against a blank at $515 \mathrm{~nm}$ using a spectrophotometer. The meat extracts at the amount of $0.2 \mathrm{ml}$ were added to $3.8 \mathrm{ml}$ of DPPH solution in the cuvette, and the absorbance was measured after $10 \mathrm{~min}\left(\mathrm{~A}_{10}\right)$. The measurements were performed in two replications.

The inhibition percentage of the DPPH radical by the samples was calculated according to the formula:

$\%$ inhibition $=\left(\mathrm{A}_{0}-\mathrm{A}_{10} / \mathrm{A}_{0}\right) \times 100$

$\mathrm{A}_{0}$ is the absorbance of the control at $\mathrm{t}=0 \mathrm{~min}$

$\mathrm{A}_{10}$ is the absorbance of the antioxidant at $\mathrm{t}=10 \mathrm{~min}$

Statistical analysis

Mean and standard deviation were computed using Microsoft Office Excel 2003. Significance $(P<0.05)$ was estimated by analysis of variance (ANOVA), with post hoc Tukey test for finding differences between the groups of pigs, using SPSS 20 statistical software (IBM Corporation, Armonk, USA).

\section{Results}

\section{Content of free fatty acids}

Differences in fat hydrolysis were observed among evaluated groups of pigs, which led to formation of FFA. When all the samples of muscles/cuts were included in the evaluation, significant differences $(P<0.001)$ were observed in the FFA content of muscles from entire males $(0.72 \pm 0.20)$ and from sows $(0.84 \pm 0.26)$. Significant differences $(P<0.05)$ were also found in the FFA content between muscles of immunocastrated males $(0.74 \pm 0.22)$ and sows. However, no significant differences were found between the investigated groups of pigs when individual samples (muscles/cuts) were analysed separately (Table 1).

Table 1 . FFA content ( $\%$ total fat as oleic acid, mean \pm SD) in different cuts/muscles of pigs (surgically castrated, immunocastrated, entire males, and sows).

\begin{tabular}{|c|c|c|c|c|c|}
\hline Muscles/cuts & $\begin{array}{l}\text { Surgically castrated } \\
\text { male pigs }\end{array}$ & Entire male pigs & $\begin{array}{l}\text { Immunocastrated } \\
\text { male pigs }\end{array}$ & Sows & $P$ \\
\hline Neck & $0.64 \pm 0.17$ & $0.62 \pm 0.15$ & $0.61 \pm 0.17$ & $0.73 \pm 0.26$ & NS \\
\hline M. longissimus dorsi & $0.71 \pm 0.15$ & $0.70 \pm 0.13$ & $0.72 \pm 0.15$ & $0.81 \pm 0.25$ & NS \\
\hline Belly & $1.01 \pm 0.37$ & $0.82 \pm 0.33$ & $0.92 \pm 0.18$ & $1.00 \pm 0.27$ & NS \\
\hline M. adductor & $0.70 \pm 0.19$ & $0.67 \pm 0.11$ & $0.73 \pm 0.20$ & $0.76 \pm 0.23$ & NS \\
\hline M. biceps femoris & $0.75 \pm 0.14$ & $0.73 \pm 0.16$ & $0.71 \pm 0.21$ & $0.86 \pm 0.26$ & NS \\
\hline M. semitendinosus & $0.80 \pm 0.13$ & $0.76 \pm 0.21$ & $0.76 \pm 0.29$ & $0.88 \pm 0.28$ & NS \\
\hline
\end{tabular}

$\mathrm{FFA}=$ free fatty acids; $\mathrm{SD}=$ standard deviation; $P=$ significance $; \mathrm{NS}=$ not significant

\section{Content of TBARS}

The oxidation process was evaluated by the TBARS content. Differences $(P<0.05)$ were observed between group of sows $\left(0.52 \pm 0.24 \mathrm{mg} \mathrm{MDA} \cdot \mathrm{kg}^{-1}\right)$ and entire males $\left(0.63 \pm 0.30 \mathrm{mg} \mathrm{MDA} \cdot \mathrm{kg}^{-1}\right)$. The difference between sows and immunocastrated pigs 
$\left(0.60 \pm 0.26 \mathrm{mg} \mathrm{MDA} \cdot \mathrm{kg}^{-1}\right)$ was less pronounced and not significant $(P=0.052)$. In the analysis of the individual muscles/cuts the difference between entire males and sows was confirmed only in m. longissimus dorsi, whereas no differences were confirmed in other muscles/cuts (Table 2).

Table 2. TBARS content ( $\mathrm{mg}$ MDA $\cdot \mathrm{kg}^{-1}$, mean $\pm \mathrm{SD}$ ) in different cuts/muscles of pigs (surgically castrated, immunocastrated, entire males, and sows).

\begin{tabular}{lccccc}
\hline Muscles/cuts & $\begin{array}{c}\text { Surgically castrated } \\
\text { male pigs }\end{array}$ & Entire male pigs & $\begin{array}{c}\text { Immunocastrated } \\
\text { male pigs }\end{array}$ & Sows & $P$ \\
\hline Neck & $0.64 \pm 0.24$ & $0.65 \pm 0.35$ & $0.67 \pm 0.16$ & $0.56 \pm 0.26$ & NS \\
M. longissimus dorsi & $0.49 \pm 0.15^{\text {ab }}$ & $0.64 \pm 0.27^{\mathrm{a}}$ & $0.52 \pm 0.21^{\mathrm{ab}}$ & $0.36 \pm 0.19^{\mathrm{b}}$ & $*$ \\
Belly & $0.70 \pm 0.28$ & $0.70 \pm 0.28$ & $0.75 \pm 0.39$ & $0.55 \pm 0.21$ & $\mathrm{NS}$ \\
M. adductor & $0.56 \pm 0.23$ & $0.58 \pm 0.24$ & $0.52 \pm 0.22$ & $0.52 \pm 0.25$ & $\mathrm{NS}$ \\
M. biceps femoris & $0.50 \pm 0.23$ & $0.59 \pm 0.30$ & $0.58 \pm 0.22$ & $0.52 \pm 0.21$ & $\mathrm{NS}$ \\
M. semitendinosus & $0.53 \pm 0.17$ & $0.60 \pm 0.35$ & $0.59 \pm 0.25$ & $0.58 \pm 0.31$ & $\mathrm{NS}$ \\
\hline
\end{tabular}

TBARS $=$ thiobarbituric reactive substances; $\mathrm{SD}=$ standard deviation; $P=$ significance; $\mathrm{NS}=$ not significant; $* P<0.05$;

a,b significant differences between groups

\section{Antioxidant capacity}

Considerable differences were found in the antioxidant capacity of pork between the groups of pigs (surgically castrated males, immunocastrated males, entire males and sows). In general, DPPH percentage inhibition values were the highest in samples from surgically castrated pigs and the lowest in samples from entire males. The differences between these two groups of pigs were significant $(P<0.05)$ in all the muscles/cuts with exception of $\mathrm{m}$. internal oblique and $\mathrm{m}$. semitendinosus. The antioxidant capacity in $\mathrm{m}$. longissimus dorsi and backfat of surgically castrated pigs was significantly $(P<0.05)$ higher than in other groups (entire males, immunocastrated males, and sows). Differences in the antioxidant capacity values among various cuts (muscles) were observed among groups (surgically castrated males, immunocastrated males, entire males, and sows), with the highest DPPH percentage inhibition values in $\mathrm{m}$. serratus and $\mathrm{m}$. semitendinosus versus the lowest values in $\mathrm{m}$. longissimus dorsi (Table 3).

Table 3. Antioxidant capacity (mean \pm SD of DPPH \% inhibition) in different cuts/muscles of pigs (surgically castrated, immunocastrated, entire males, and sows).

\begin{tabular}{lccccc}
\hline Muscles/cuts & $\begin{array}{c}\text { Surgically castrated } \\
\text { male pigs }\end{array}$ & Entire male pigs & $\begin{array}{c}\text { Immunocastrated } \\
\text { male pigs }\end{array}$ & Sows & $P$ \\
\hline M. serratus & $30.93 \pm 1.30^{\mathrm{a}}$ & $29.77 \pm 2.59^{\mathrm{b}}$ & $29.49 \pm 2.35^{\mathrm{b}}$ & $31.10 \pm 1.75^{\mathrm{a}}$ & $*$ \\
M. longissimus dorsi & $25.16 \pm 1.63^{\mathrm{a}}$ & $23.53 \pm 1.45^{\mathrm{b}}$ & $24.22 \pm 1.44^{\mathrm{b}}$ & $23.98 \pm 1.35^{\mathrm{b}}$ & $*$ \\
M. internal oblique & $28.44 \pm 2.19$ & $27.91 \pm 2.07$ & $27.82 \pm 1.51$ & $28.40 \pm 1.40$ & $\mathrm{NS}$ \\
M. adductor & $25.19 \pm 1.17^{\mathrm{a}}$ & $24.33 \pm 1.42^{\mathrm{b}}$ & $25.17 \pm 1.34^{\mathrm{a}}$ & $25.41 \pm 2.01^{\mathrm{a}}$ & $*$ \\
Jowl & $29.42 \pm 2.18^{\mathrm{a}}$ & $29.59 \pm 7.64^{\mathrm{b}}$ & $27.57 \pm 1.88^{\mathrm{b}}$ & $29.03 \pm 1.93^{\mathrm{a}}$ & $*$ \\
Back fat & $29.42 \pm 5.04^{\mathrm{a}}$ & $27.26 \pm 1.33^{\mathrm{b}}$ & $27.72 \pm 1.47^{\mathrm{b}}$ & $27.76 \pm 1.79^{\mathrm{b}}$ & $*$ \\
M. triceps brachii & $29.87 \pm 3.86^{\mathrm{a}}$ & $27.94 \pm 3.83^{\mathrm{b}}$ & $28.24 \pm 2.39^{\mathrm{ab}}$ & $28.05 \pm 2.38^{\mathrm{ab}}$ & $*$ \\
M. biceps femoris & $26.93 \pm 1.56^{\mathrm{a}}$ & $25.96 \pm 1.85^{\mathrm{b}}$ & $26.56 \pm 2.08^{\mathrm{ab}}$ & $26.54 \pm 1.61^{\mathrm{ab}}$ & $*$ \\
M. semitendinosus & $29.57 \pm 3.93$ & $29.86 \pm 4.33$ & $29.84 \pm 4.62$ & $30.55 \pm 4.58$ & $\mathrm{NS}$ \\
\hline
\end{tabular}

$\mathrm{DPPH}=2,2$-diphenyl-1-picrylhydrazyl; $\mathrm{SD}=$ standard deviation; $P=$ significance; $\mathrm{NS}=$ not significant; $* P<0.05 ;{ }^{\mathrm{a}, \mathrm{b}}$ significant differences between groups 


\section{Discussion}

\section{Content of free fatty acids}

It is a well-known fact that FFA are products of enzymatic hydrolysis of esterified lipids. Free fatty acids may also take part in a reaction with myofibrillar proteins, and enhance protein aggregation. Free fatty acids may have a pro-oxidant effect on lipid matter, which is attributed to the catalytic effect of the carboxyl group on the formation of free radicals in the decomposition of hydroperoxides (Özyurt et al. 2009; Bahmani et al. 2011). The FFA concentration in the present study decreased in the order of sows $>$ surgically castrated males $>$ immunologically castrated males $>$ entire males. Egea et al. (2016) reported that castrated males had a higher SFA content than sows $(P<0.05)$, whereas the PUFA levels were lower $(P<0.001)$. Relative concentration of linoleic acid and PUFA in the back fat decreased in the order of entire males $>$ sows $>$ castrated males, while the saturated fatty acid percentage increased in the same order (Nürnberg et al. 1998). Zhang et al. (2007) pointed to the effect of sex on the specific enzyme activities involved in long chain PUFA metabolism.

\section{Content of TBARS}

Differences between the TBARS content in sows and entire males in this study correlated with the differences in the FFA content. Grela et al. (2013) did not find differences between entire males, surgically castrated or immunocastrated pigs, and sows. The mean content of TBARS they found was $0.35-0.37 \mathrm{mg} \mathrm{MDA} \cdot \mathrm{kg}^{-1}$ of meat, which was lower than in our study (0.52-0.63 $\left.\mathrm{mg} \mathrm{MDA} \cdot \mathrm{kg}^{-1}\right)$. Jones-Hamlow et al. (2016) observed that lipid oxidation was increased $(P=0.05)$ in sausage manufactured from surgically castrated $(\mathrm{PC})$ pigs $\left(0.47 \mathrm{mg} \mathrm{MDA} \cdot \mathrm{kg}^{-1}\right.$ of meat) compared to sausages from immunologically castrated (IC) pigs (0.22 mg MDA $\mathrm{kg}^{-1}$ of meat), although an increase in TBARS was predicted in IC pigs. Tavárez et al. (2014) demonstrated that at 6-8 weeks after the second vaccination of IC against GnRH, PUFA content was similar between IC and PC pigs.

\section{Antioxidant capacity}

The oxidative stability of meat is dependent on the balance between antioxidants and pro-oxidants (such as PUFA concentration or free iron) (Florek et al. 2012). Low antioxidant levels (vitamin E) in pig tissues containing high PUFA concentrations are due to the utilization of the antioxidant to control oxidation (Kouba et al. 2003). The fat of surgically castrated pigs (both intramuscular and back fat) showed the lowest content of PUFA (pro-oxidant) in comparison with entire males, immunocastrated males and gilts (Grela et al. 2013). Proportions of pro-oxidant represented by PUFA tend to be high in subcutaneous adipose tissue from entire males due to lesser tissue maturation. Quality of fat tends to be lower in entire males than in castrates and sows, due to a higher proportion of water and a lower proportion of lipid (Wood et al. 2008). Hogberg et al. (2001) suggested that reduction of sex hormones in castrates might affect the rate of elongation and desaturation of fatty acids (18:2n-6 and 18:3n-3) to highly polyunsaturated fatty acids. Free radical formation resulted from the metabolism of skatole by cytochrome P-450-dependent mixed function oxidases (MFO) or prostaglandin H synthase (PHS). Such free radicals promote lipid peroxidation, especially of highly unsaturated fatty acids (Bray and Kirkland 1990). Thus, the aforementioned possible explanation might be behind the differences in the antioxidant capacity between the tissues of surgically castrated pigs and other evaluated groups of pigs in the present research. Compositions of endogenous antioxidants can differ among meats of different species, among animals of the same species and even individual muscle types (Pradhan et al. 2000; Descalzo and Sancho 2008; Serpen et al. 2012). Lipid-soluble antioxidants in animal tissues play an important role 
in delaying the oxidative deterioration of meat, represented by myoglobin oxidation and development of rancid odours from PUFA degradation (Wood and Enser 1997). Thus, the differences of antioxidant capacity in our study could be attributed to the differences in myoglobin pigment concentration and intramuscular lipid in the different muscles of pig carcass. Damgaard et al. (2014) suggested that the mode of action of some antioxidants is represented by impairing the oxidation via binding hemin which acts as oxidation initiator. High content of antioxidant peptides or high concentration of heme pigments in some porcine tissues could act as iron chelators, resulting in improved oxidation stability.

Surgical castration of pigs is the traditional method in most of countries. Immunocastration is recommended as an alternative method in terms of animal welfare. Regarding FFA and TBARS some inconclusive differences were found in this work, probably resulting from different composition of fatty acids and the effect of sex on specific enzyme activities. Due to this finding future studies on fatty acid composition are needed to support or disprove this hypothesis. This study found that the antioxidant capacity in different muscles/cuts of pigs was affected positively by surgical castration. The topic requires involvement of other methods for antioxidant detection and correlation with pro-oxidants.

\section{Acknowledgements}

This work was carried out under the project CasPigMeat - A complex analysis of impact of traditional (surgical) and alternative methods of castration on pig rearing and pork quality in order to ensure sustainable and competitive pork production in the Czech Republic (QJ1510233), financially supported by the Ministry of Agriculture of the Czech Republic.

\section{References}

Babol J, Squires EJ 1995: Quality of meat from entire male pigs. Food Res Int 28: 201-212

Bahmani ZA, Rezai M, Hosseini SV, Regenstein JM, Böhme K, Alishahi A, Yadollahi F 2011: Chilled storage of golden grey mullet (Liza aurata). LWT-Food Sci Technol 44: 1894-1900

Bañón S, Andreu C, Laencina J, Garrido MD 2004: Fresh and eating pork quality from entire versus castrate heavy males. Food Qual Prefer 15: 293-300

Boler DD, Killefer J, Meeuwse DM, King VL, McKeith FK, Dilger AC 2012: Effects of slaughter time post-second injection on carcass cutting yields and bacon characteristics of immunologically castrated male pigs. J Anim Sci 90: 334-344

Bray TM, Kirkland JB 1990: The metabolic basis of 3-methylindole-induced pneumotoxicity. Pharmacol Therapeut 46: 105-118

Castellini C, Mugnai C, Dal Bosco A 2002: Effect of organic production system on broiler carcass and meat quality. Meat Sci 60: $219-225$

CSN EN ISO 660 (588756) Animal and vegetable fats and oils - Determination of acid value and acidity, Czech office for standards, metrology and testing, 2009, $20 \mathrm{p}$.

Damgaard TD, Otte JAH, Meinert L, Jensen K, Lametsch R 2014: Antioxidant capacity of hydrolyzed porcine tissues. Food Sci and Nutr 3: 282-288

Descalzo AM, Sancho AM 2008: A review of natural antioxidants and their effects on oxidative status, odor and quality of fresh beef produced in Argentina. Meat Sci 79: 423-436

DG-SANCO 2010. European Declaration on Alternatives to Surgical Castration of Pigs. http://ec.europa.eu/food/ animal/welfare/farm/initiatives en.htm Accessed: 16/02/2015

Dunshea FR, Colantoni C, Howard K, McCauley I, Jackson P, Long KA, Hennessy DP 2001: Vaccination of boars with a GnRH vaccine (Improvac) eliminates boar taint and increases growth performance. J Anim Sci 79: 2524-2535

Egea M, Linares MB, Garrido MD, Madrid J, Hernández F 2016: Feeding Iberian $\times$ Duroc cross pigs with crude glycerine: Effects of diet and gender on carcass and meat quality. Meta Sci 111: 78-84

Florek M, Litwińczuk Z, Skałecki P, Kędzierska-Matysek M, Grodzicki T 2012: Chemical composition and inherent properties of offal from calves maintained under two production systems. Meat Sci 90: 402-409

Fredriksen B, Font FM, Lundstrom K, Migdal W, Prunier A, Tuyttens FAM and Bonneau M 2009: Practice on castration of piglets in Europe. Animal 3: 1480-1487

Grela ER, Kowalczuk-Vasilev E. Klebaniuk R 2013: Performance, pork quality and fatty acid composition of entire males, surgically castrated or immunocastrated males and female pigs reared under organic system. Pol J Vet Sci 16: 107-114 
Grotto D, Santa Maria L, Valentini J, Paniz C, Schmitt G, Garcia SC, Pomblum VJ, Rocha JBT, Farina M 2009: Importance of the lipid peroxidation biomarkers and methodological aspects for malondialdehyde quantification. Quim. Nova 32: 169-174

Harris EK, Mellencamp MA, Johnston LJ, Cox RB, Shurson GC 2018: Effectiveness of different corn dried distillers grains with solubles feeding strategies and increasing the time intervals between the second Improvest dose and slaughter of immunologically castrated pigs on belly and pork fat quality. Meat Sci 135: 62-73

Heilerová L, Bučková M, Tarapčík P, Šilhár S, Labuda J 2003: Comparison of antioxidative activity data for aqueous extracts of lemon balm (Melissa officinalis L.), oregano (Oreganum vulgare L.), thyme (Thymus vulgaris L.) and agrimony (Agrimonia eupatoria L.) obtained by conventional methods and the DNA-based biosensor. Czech J Food Sci 21: 78-84

Hogberg A, Pickova J, Dutta PC, Babol J, Bylund AC 2001: Effect of rearing system on muscle lipids of gilts and castrated male pigs. Meat Sci 58: 223-229

Huang Y, Gan Y, Li F, Yan Ch, Li H, Feng Q 2015: Effects of high pressure in combination with thermal treatment on lipid hydrolysis and oxidation in pork. LWT - Food Sci and Technol 63: 136-143

Jones-Hamlow KA, Tavárez MA, Shroeder AL, Dilger AC 2016: Lipid oxidation, sensory characteristics, and color of fresh pork sausage from immunologically castrated pigs stored frozen for up to 12 weeks. Food Sci Nutr 4: 355-363

Jung S, Choe JH, Kim B, Yun H, Kruk ZA, Jo C 2010: Effect of dietary mixture of gallic acid and linoleic acid on antioxidative potential and quality of breast meat from broilers. Meat Sci 86: $520-526$

Karwowska M, Dolatowski ZJ 2014: Effect of mustard on lipid oxidation in model pork meat product. Eur J Lipid Sci Technol 116: 311-318

Kouba M, Enser M, Whittington FM, Nute GR, Wood JD 2003: Effect of a high-linolenic acid diet on lipogenic enzyme activities, fatty acid composition and meat quality in the growing pig. J Anim Sci 81: 1967-1979

Nürnberg K, Wegner J, Ender K 1998: Factors influencing fat composition in muscle and adipose tissue of farm animals. Livestock Prod Sci 56: 145-156

Özyurt G, Kuley E, Özkütük S, Özogul F 2009: Sensory, microbiological and chemical assessment of the freshness of red mullet (Mullus barbatus) and goldband goatfish (Upeneus moluccensis) during storage in ice. Food Chem 114: 505-510

Pauly C, Luginbühl W, Ampuero S, Bee G 2012: Expected effects on carcass and pork quality when surgical castration is omitted - Results of a meta-analysis study. Meat Sci 92: 858-862

Pradhan AA, Rhee KS, Hernandez P 2000: Stability of catalase and its potential role in lipid oxidation in meat. Meat Sci 54: 385-390

Ripoll G, Lobón S, Joy M 2018: Use of visible and near infrared reflectance spectra to predict lipid peroxidation of light lamb meat and discriminate dam's feeding systems. Meat Sci 143: 24-29

Serpen A, Gökmen V, Fogliano V 2012: Total antioxidant capacities of raw and cooked meats. Meat Sci 90: 60-65

Tavárez MA, Bohrer BM, Asmus MD, Schroeder AL, Matulis RJ, Boler DD, Dilger AC 2014: Effects of immunological castration and distiller's dried grains with solubles on carcass cutability and commercial bacon slicing yields of barrows slaughtered at two time points. J Anim Sci 92: 3149-3160

Wood JD, Enser M 1997: Factors influencing fatty acids in meat and the role of antioxidants in improving meat quality. Brit J Nutr 78: S49-S60

Wood JD, Enser M, Fisher AV, Nute, GR, Sheard PR, Richardson RI, Hughes SI, Whittington FM 2008: Fat deposition, fatty acid composition and meat quality: A review. Meat Sci 78: 343-358

Zhang S, Knight TJ, Stalder KJ, Goodwin RN, Lonergan SM, Beitz DC 2007: Effect of breed, sex and halothane genotype on fatty acid composition of pork longissimus muscle. J Animal Sci 85: 583-591 